\title{
$\nabla$ \\ Quality Attributes of Value Added Tarts Developed from Lotus (Nelumbo nucifera) Seed Powder
}

\author{
IJCRR \\ Section: Healthcare \\ Sci. Journal Impact \\ Factor: 6.1 (2018) \\ ICV: 90.90 (2018)

\section{Jyoti Kumari ${ }^{1}$, Arivuchudar $\mathbf{R}^{2}$}

${ }^{1,2}$ Department of Nutrition and Dietetics, Periyar University, Salem - 636011, India.

\section{ABSTRACT}

Background: The consumer preference for snack product is on a huge rise, which is evident from the increase in revenue generated by the snack food industries. Also, the increase in nutritional awareness has posed a demand to develop nutritious snack products for bingeing. The tarts are extremely attractive and relished high-calorie snack by people of all age groups. The lotus seed with pharmaceutical properties is underutilised and hence used in this study to balance the empty calories provided by tarts.

Objective: This study is aimed at developing high-quality tarts by incorporating lotus seed powder.

Method: The lotus seed powder was substituted into the wheat flour at 0, 25, 50 and $75 \%$ to prepare tarts. All the variations of lotus seed powder incorporated tarts were analysed for physical and organoleptic attributes. The most accepted variation by the panel members was further subjected to nutrient analysis.

Results: The results showed that the nutrients like carbohydrate and protein are more in the accepted variation (75\% of lotus seed powder incorporation) of value-added tart while fat was lower. The quantity of fibre was also more in $75 \%$ lotus seed powder incorporated tart compared to the control tart. The vitamins thiamine, riboflavin, niacin, vitamin B5 and B6 were more in the value-added tart and minerals, calcium, potassium, iron, magnesium and zinc were also more compared to the control tart.

Conclusion: The value addition with lotus seed powder, to the most savoured bakery products like tart, will ascertain adequate nutrition without compromising the taste of original tarts.

Key Words: Lotus Seed, Phytonutrients, Tart, Value Addition

\section{INTRODUCTION}

Lotus seeds obtained from lotus flowers (Nelumbo nucifera), with lots of medicinal values, have not gained popularity like that of the lotus flower. Though lotus seeds are not consumed as a dietary product, it is being used extensively in Chinese medicine. The type of lotus seeds available commercially is either brown peel or white variety. White lotus seeds which are de-shelled and de-membraned are white, while in the brown peel lotus seeds the membrane adheres to the seeds.

The nutritional and nutraceutical parameters of lotus seeds are noteworthy. Lotus seeds contribute to key nutrients namely starch, carbohydrates, protein and fat, chiefly unsaturated fatty acids. ${ }^{1}$ The nutraceutical components like asparagines, gallic acid and alkaloids such as demethylcolaurine, isoliensinine, liensinine, Lotusine, methylocrypalline, neferine, nuciferine, and pronuciferine, flavonoids like galuteolin, hyperine, rutin and minerals such as zinc, iron, calcium and magnesium are found in significant amounts in mature lotus seeds. ${ }^{2}$ The presence of these nutraceuticals help in alleviating conditions such as inflammation or infection in tissues and skin, tumours, and acts as an antidote for poison. ${ }^{3}$ Lotus seeds are also used in the treatment of hyperdipsia, halitosis, menorrhagia, leprosy and fever. ${ }^{4}$ The roasted lotus seeds can be substituted for coffee seeds and it also possesses saponins and phenolics in appreciable quantities. ${ }^{5}$

The health effects of N.nucifera seeds on animals have been studied by many researchers. Hydro-alcoholic extract from $N$. Nucifera seeds showed potent free-radical scavenging ability. ${ }^{6}$ Immunologic effect was observed in mice, where ethanolic lotus seed extract caused a significant increase in total and differential leukocyte and lymphocyte count. ${ }^{7}$ The neferine, an alkaloid present in the lotus seed has shown to have

\section{Corresponding Author:}

Mrs. R. Arivuchudar, Assistant Professor, Department of Nutrition and Dietetics, Periyar University, Salem-636011, India. E-mail: achudar24@gmail.com

ISSN: 2231-2196 (Print)

Received: 11.08 .2020
ISSN: 0975-5241 (Online)

Revised: 27.09 .2020
Accepted: 22.10 .2020 
anti-arrhythmic action and also significantly inhibited platelet aggregation in mice. ${ }^{8}$ In animal study, the trace elements present in lotus seed play a significant role in maintaining blood glucose levels. ${ }^{9}$ By inhibiting acetylcholinesterase activity and inducing choline acetyltransferase expression, the lotus seed extract improved scopolamine-induced dementia in rats. ${ }^{10}$ Lotus seeds also possess antiviral activity. The lotus seed extract's inhibitory effects on herpes simplex virus type 1 (HSV-1) have been reported..$^{11}$ In rats on a high-fat diet, $N$. nucifera seeds reduced adipose tissue weights, ameliorated blood lipid profile and modulated serum leptin level. ${ }^{12}$

The lotus seeds with various potent nutrients can be used to enhance the nutritional quality of many foods which provide empty calories. Tarts being one of the favourite bakery foods is high in calories and many obese children and obese diabetic adults are deprived of eating tarts. Hence, value addition to tart by incorporating the lotus seed powder will help in improving the nutritional parameters.

\section{MATERIALS AND METHODS}

\section{Procurement and Processing of Raw Material}

Different ingredients for the development of value-added tart, like raw lotus seed, wheat flour, as well as other ingredients like butter, honey were procured from the local departmental store in Jharkhand.

\section{Processing of Lotus Seed}

Lotus seeds were purchased and checked for any infestation or damage. Lotus seeds free from damage were washed in clean water, dried under sunlight and ground to a fine powder.

\section{Formulation of Lotus Seed Powder Incorpo- rated Tart}

The fresh lotus seed was washed in clean water, dried under the sun for 12 hours until free from moisture. The dried lotus seed was then ground in a mixer and sieved. Fine lotus seed powder and wheat flour were blended in the required proportions as given in the Table 1along with butter, and a pinch of salt. Knead all the ingredients with the required amount of water and make a stiff dough. Take a small piece of dough, roll it flat and put it in the tart maker to give the shape of the tart. Bake in the oven at $170^{\circ} \mathrm{C}$ for 20 minutes and the tart crust is done (Table 1).

The lotus seed paste is made by grinding $10 \mathrm{gms}$ of lotus seed with water. The paste obtained is cooked with honey and butter and the tart crust is filled with lotus seed paste evenly for all variations.
Table 1: Ingredients in the Preparation of Tart Crust

\begin{tabular}{lcccc} 
Ingredients & \multicolumn{4}{c}{ Level of Incorporation } \\
& Control & $\mathbf{V}_{\mathbf{1}}$ & $\mathbf{V}_{\mathbf{2}}$ & $\mathbf{V}_{\mathbf{3}}$ \\
\hline Lotus seed powder (gms) & - & 25 & 50 & 75 \\
Wheat flour (gms) & 100 & 75 & 50 & 25 \\
Butter (gms) & 20 & 20 & 20 & 20 \\
Honey (gms) & 5 & 5 & 5 & 5 \\
\hline
\end{tabular}

\section{Statistical Analysis}

All experiments in the present analysis were conducted in triplicate, and mean values were reported.

\section{RESULTS AND DISCUSSION}

The results and discussion about the study Quality Attributes of Value Added Tarts Developed from Lotus (Nelumbo nucifera) Seed Powder is presented below.

\section{Physical Characteristics of the Lotus Seed Powder Incorporated Tarts and Control Tart}

The physical characteristics such as thickness, diameter, spread ratio and breaking strength were studied in the developed variations of lotus seed powder incorporated tarts and the results are presented in Table 2.

Table 2: Physical Characteristics of the Lotus Seed Powder Incorporated Tarts and Control Tart

\begin{tabular}{llcccc} 
S. No & $\begin{array}{l}\text { Physical Character- } \\
\text { istics }\end{array}$ & Calues \\
1. & Thickness (cms) & 0.65 & 0.8 & 0.75 & 0.7 \\
2. & Diameter (cms) & 6 & 6 & 6 & 6 \\
3. & Spread ratio & 9.2 & 7.5 & 8 & 8.5 \\
4. & Breaking strength (g) & 142 & 136 & 139 & 140 \\
\hline
\end{tabular}

The above table depicts the physical characteristics of values of control and lotus seed powder incorporated tarts. Tart with desirable the quality is achieved when the spread ratio is more ${ }^{13}$ Hardness is considered as an important characteristic which is measured as the peak force required to break the food product. ${ }^{14}$ It is observed that more the incorporation of lotus seed powder more is the spread ratio and more is the breaking strength. Breaking strength correlates with the hardness of the tart. The more spread ratio and higher breaking strength in variation 3 , proves that the capacity to hold the fillings and to achieve the desirable mouth feel is favourable in variation 3 , which has 75 gms of lotus seed powder incorporated. 


\section{Organoleptic Evaluation of Different Variations of Lotus Seed Powder Incorporated Tarts and Control Tart.}

Five-point hedonic rating scale method was adopted to estimate the acceptance of the developed products. Totally 30 semi-trained people were used for organoleptic analysis. The sensory parameters like appearance, texture, flavour, mouthfeel, taste and overall acceptability of the value-added tart developed by incorporating lotus seed powder in various proportions was assessed.

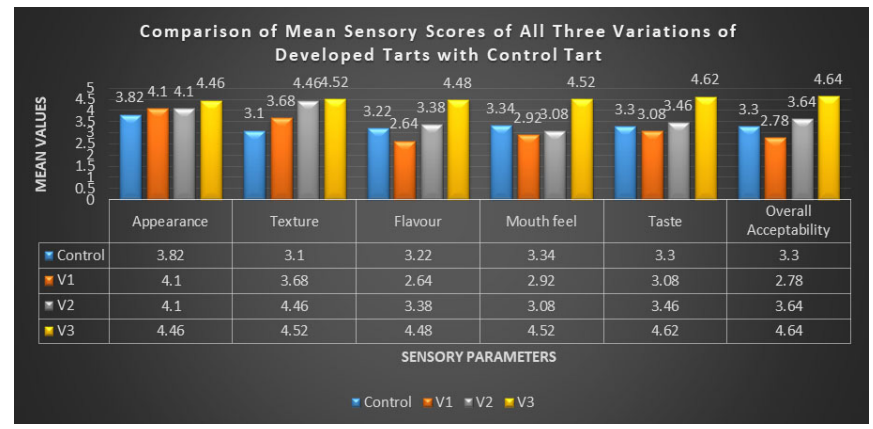

Figure 1: Organoleptic Evaluation of the Lotus Seed Powder Incorporated Tarts and Control Tart.

The success of a food product formulated does not end with its preparation, rather the acceptability by the consumers determine it. ${ }^{15}$ From the above figure 1 of organoleptic evaluation, it can be concluded that the variation 3 , tart with lotus seed powder incorporated at $75 \%$ level scored comparatively higher in terms of all the sensory parameters like appearance, taste, texture, flavour and mouthfeel. The mean score for overall acceptability was 4.64 and also very much higher compared to the overall acceptability mean value of control tart, which was 3.3. An organoleptic study by Kaur et al. on various value-added bakery products like biscuits, muffins, bread, doughnuts and tarts by incorporating soybean flour have proved that tarts were highly acceptable. ${ }^{16} \mathrm{Also}$, in this study based on the organoleptic evaluation, variation 3 tarts with $75 \%$ of incorporation of lotus seed flour was found to be most acceptable by the panel members and the proportion of lotus seed powder incorporation was directly proportional to the level of acceptance of the tart and this was further subjected to nutritional analysis.

\section{Nutrient Content of the Accepted Variation of Tart}

Nelumbo nuciferagaertn, belonging to the Nymphaeaceae family is an aquatic perennial widely planted in eastern Asia and cultivated for food and drink. According to folk medicine, it was traditionally used for dispersing summer heat. Numerous papers have mentioned the pharmacologically and physiologically activities of lotus seed, including antioxidant, anti-HIV and antiobesity effects.
Table 3: Nutrient Content of Accepted Variation of Lotus Seed Powder Incorporated Tarts and Control Tart

\begin{tabular}{|c|c|c|}
\hline Parameters & $\begin{array}{c}\text { Nutrient } \\
\text { content } \\
\text { of control } \\
\text { Tart }\end{array}$ & $\begin{array}{c}\text { Nutrient Con- } \\
\text { tent of Accept- } \\
\text { ed Variation of } \\
\text { Tart with } 75 \mathrm{gms} \\
\text { of Lotus Seed } \\
\text { Powder }\end{array}$ \\
\hline Moisture, g/10og & 15.4 & 15.7 \\
\hline Carbohydrates, g/1oog & 46.8 & 66.1 \\
\hline Protein , g/10og & 11.7 & 12.8 \\
\hline Total Fat, g/10og & 14.2 & 5.6 \\
\hline Fibre, $g / 100 g$ & 1.6 & 4.8 \\
\hline Thiamine, mg/ıog & 0.4 & 1.4 \\
\hline Riboflavin ,mg/10og & 0.1 & 1.8 \\
\hline Niacin , mg/10og & 1.0 & 1.2 \\
\hline Pantothenic acid ,mg/1oog & 0.6 & 1.1 \\
\hline Vitamin B6, mg/ıog & 0.3 & 1.1 \\
\hline Calcium ,mg/10og & 115 & 142 \\
\hline Potassium ,mg/1oog & 362.4 & 983 \\
\hline Manganese, mg/ıoog & 1.8 & 1.8 \\
\hline Iron , mg/10og & 1.2 & 1.9 \\
\hline Magnesium, mg/1oog & 84 & 186 \\
\hline Zinc, mg/ıoog & 0.6 & 0.8 \\
\hline
\end{tabular}

The above table predicts that the lotus seed powder incorporation in the tart has added nutritional value to the control tart. Nutrients like carbohydrate and protein are more in the accepted variation of value-added tart viz. $66.1 \mathrm{gms}$ and $12.8 \mathrm{gms}$, while fat $(5.6 \mathrm{gms})$ is lower and fibre $(4.8 \mathrm{gms})$ is more in lotus seed incorporated tart compared to the control tart. The vitamins thiamine, riboflavin, niacin, vitamin B5 and $\mathrm{B} 6$ are more in the value-added tart. The accepted variation of lotus seed powder incorporated tart contains $1.4 \mathrm{mg}$ of B1, 1.8mg of B2, 1.2mg of B3, $1.1 \mathrm{mg}$ of B5 and B6. On comparing the mineral content, except manganese, all other minerals are more in lotus seed powder incorporated tart ( table 3 ). The lotus seed powder incorporated tart contains $142 \mathrm{mg}$ of calcium, $983 \mathrm{mg}$ of potassium, $1.8 \mathrm{mg}$ of manganese, $1.9 \mathrm{mg}$ of iron, $186 \mathrm{mg}$ of magnesium and $0.8 \mathrm{mg}$ of zinc, all the nutrient values are on the higher side compared to the control tart. A similar study on lotus seed powder incorporated at 5\% level in noodles was found low in fat, high in fibre, ash and phenols. ${ }^{17}$ Thus, value addition improves the nutritional quality and consumable supremacy of any food product.

\section{CONCLUSION}


The health benefits of lotus seed powder is massive. Lotus seed powder improves appetite. Their low sodium and high magnesium content are effective in treating heart disease, diabetes and high blood pressure. The astringent properties help stop chronic diarrhoea. These seeds contain an antiageing enzyme, which repairs the damaged protein and heal the skin. The calming effects and the sedative properties of the seeds are effective in restlessness and to treat insomnia. Lotus seed consists of flavonoids like quercetin that have an anti-hemorrhagic effect and therefore can avoid excessive bleeding by improving the strength of the wall of capillaries. Nelumbo nucifera seeds contain neuroprotective flavonoids such as kaempferol, quercetin, isorhamnetin and myricetin. Polyphenols of lotus seeds are complex phenolic secondary metabolites, hence have powerful inhibitory effects on microorganisms. Hence, this study done to incorporate the wellness of lotus seeds into the most enjoyed bakery product tart, to enhance its nutritional value and to disseminate the goodness of nutrients to the tart consuming population is fruitful.

\section{ACKNOWLEDGEMENT}

Authors acknowledge the immense help received from the scholars whose articles are cited and included in references to this manuscript. The authors are also grateful to authors/ editors/publishers of all those articles, journals and books from where the literature for this article has been reviewed and discussed.

\section{Conflict of Interest}

The authors declare no conflict of interest.

\section{Financial Support}

Nil

\section{REFERENCES}

1. Indrayan AK, Sharma S, Durgapal D, Kumar N, Kumar M. Determination of nutritive value and analysis of mineral elements for some medicinally valued plants from Uttaranchal. Curr Sci 2005; 89: 1252-1255.

2. Pal I, Dey P. A Review on Lotus (Nelumbo nucifera) Seed. Int J Sci Res 2015; 4: 1659-66.
3. Sridhar K R, Bhat R. Lotus - A potential nutraceutical source. J Agric Technol 2007; 3(1): 143-155.

4. Sujitha R, Bhimba BV, Sindhu MS, Arumugham P. Phytochemical Evaluation and Antioxidant Activity of Nelumbo nucifera, Acorus calamus and Piper longum. Int J Pharm Chem Sci 2013; 2(3): 1573-78.

5. Ling Z.Q, Xie B.J, YangE.L. Isolation, characterization, and determination of the antioxidative activity of oligomeric procyanidins from the seedpod of Nelumbo nucifera Gaertn. J Agric Food Chem 2005; 53: 2441-2445.

6. Rai S, Wahile A, Mukherjee K, Saha B.P, Mukherjee P.K.Antioxidant activity of Nelumbo nucifera (sacred lotus) seeds. J Ethnopharmacol 2006;104: 322-327.

7. Mukherjee D, Khatua TN, Venkatesh P, Saha B.P, Mukherjee P.K.Immunomodulatory potential of rhizome and seed extracts of Nelumbo nucifera Gaertn. J Ethnopharmacol 2010; 128: 490494.

8. Sugimoto Y, Furutani S, Itoh A. Effects of extracts and neferine from the embryo of Nelumbo nucifera seeds on the central nervous system. Phytomedicine 2008;15(12): 1117-1124.

9. Sivasankari S, Mani, Iyyam Pillai S, Subramanian SP, Kandaswamy M. Evaluation of hypoglycemic activity of inorganic constituents in N.nucifera seeds on streptozotocin-induced diabetes in rats. Biol Trace Elem Res 2010;138:226-237.

10. Oh JH, Choi BJ, Chang MS, Park SK. Nelumbo nucifera semen extract improves memory in rats with scopolamine-induced amnesia through the induction of choline acetyltransferase expression. Neurosci Lett 2009; 461(1): 41-44.

11. Kuo YC, Lin, YL, Liu CP, Tsai WJ. Herpes simplex virus types 1 propagation in HeLa cells interrupted by Nelumbo nucifera. J Biomed Sci 2005; 12:1021-1034.

12. You JS, Lee Y J, Kim KS, Kim SH, Chang K J. Antiobesity and hypolipidaemic effects of Nelumbo nucifera seed ethanol extract in human pre-adipocytes and rats fed a high-fat diet. J Sci Food Agric 2014;94(3):568-75.

13. Suriya M, Rajput R, Reddy CK, Haripriya S, Bashir M. Functional and physicochemical characteristics of cookies prepared from Amorphophallus paeoniifolius flour. J Food Sci Technol 2017;54(7):2156-2165.

14. Cheng YF, Bhat R. Functional, physicochemical and sensory properties of novel cookies produced by utilizing underutilized jering (Pithecellobium jiringa Jack.) legume flour. Food Biosci 2016; 14:54-61.

15. Aditi, Arivuchudar.R. A study on the organoleptic evaluation of unprocessed, sprouted and roasted flour mix chapattis. Int J Home Sci2018; 4(3): 88-92.

16. Kaur H, Kaur N. Development and sensory evaluation of value-added bakery products developed from germinated soybean (Glycine max) varieties. J Appl Nat Sci 2019; 11(1): 211-216.

17. Jirukkakul N, Sengkhamparn N. The Physicochemical Properties and Potential of the Lotus Seed Flour as Wheat Flour Substitute for Noodle. Songklanakarin J Sci Technol 2018;40(6):13541360 . 